\title{
The study of the spatio-temporal changes of drought in the Mongolian Plateau in 40 years based on TVDI
}

\author{
Cao Xiaoming ${ }^{\mathrm{a}}$, Feng Yiming ${ }^{\mathrm{a}}$, Wang Juanle ${ }^{\mathrm{b}}$, Zhiqiang Gao ${ }^{* \mathrm{c}, \mathrm{d}}$, Jicai Ning ${ }^{\mathrm{c}}$, Wei Gao ${ }^{\mathrm{d}}$ \\ a Institute of Desertification Studies, China Academy of Forestry, Beijing 100091, China \\ b State Key Laboratory of Resources and Environmental Information Systems, Institute of Geographical Sciences and \\ Natural Resources Research, Chinese Academy of Sciences, Beijing 100101, China \\ ${ }^{c}$ Yantai Institute of Coastal Zone Research,Chinese Academy of Sciences, Yantai, 264003, China \\ dUSDA UV-B Monitoring and Research Program and Center of Remote Sensing and Modeling for Agricultural Sustainability, \\ Natural Resource Ecology Laboratory, \\ Colorado State University, Fort Collins, CO, USA
}

\begin{abstract}
:
This paper presents a new drought assessment method by modifying the NDVI-Ts space, which named NDVI-Ts general space. Based on this method, the general dry side and wet side equation were established for the period of 1981 and 2010 in the Mongolian Plateau. The results showed that: 1) the NDVI-Ts general space was more stable for monitoring drought than that for the single time Remote Sensing data; 2) TVDI was lower in the areas with high latitude, high vegetation cover, well-growing vegetation, which indicated higher soil moisture.3) The dry level area was the largest one, and the normal area was the second largest, the wet level area was the third, the extremely dry and extremely wet area was the least.4)The results showed that the fluctuated area mainly occurred in the normal level and the dry level, the extremely wet level, the wet level and extremely dry level basically remained unchanged. It may be explored that, the aridification became more serious in the $1981-2012$, the area transformation mainly occurred between the normal level and dry level.
\end{abstract}

Keywords- drought assessment, Ts-NDVI space, the Mongolian plateau, TVDI

\section{Introduction}

Semi-arid regions, which are characterized by low and erraticannual precipitation, comprise $61 \%$ of Iran. Therefore, vegetationand soil water stress is a major widespread problem in the country.Drought is a common natural disaster, requiring action to monitorand detect water stress, to mitigate its negative impacts on humanlife, and wildlife and plant communities.

The Mongolian plateau is a relatively closed arid, semi-arid plateau. The status and the changes of the ecosystem have an important impact on the environment to the North China and Northeast China. So, there was important significance in the study of the changes of the surface ecological environment. The paper chose the Inner Mongolia Autonomous Region, the Mongolia and the Tuva Republic as the study area (Fig.1).

\footnotetext{
*Corresponding author. Email: gaoland@gmail.com
} 


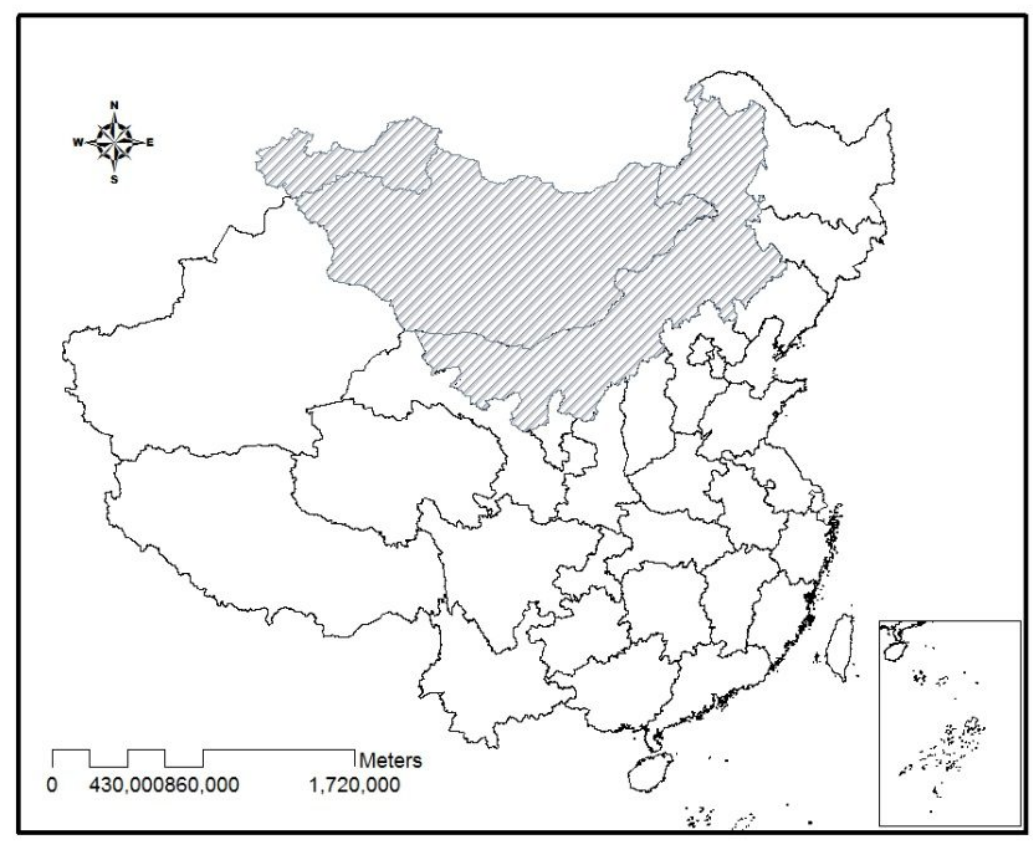

Fig.1 The study area

2 Methods and materials

\section{A. Data collection and processing}

The 10-day series AVHRR PathFinder NDVI data of the Mongolian Plateau from July, 1981 to 1999, and the 16-day series MODIS NDVI data of the Mongolian Plateau from 2000 to 2010 were collected. The monthly and annual NDVI data from 1980 to 2010 were obtained by the MVC method. The 8-day series MODIS LST data of the Mongolian Plateau from 2000 to 2010 were collected. The monthly and LST data from 2000 to 2010 were obtained with the mean value.

The 10-day measure soil moisture data were collected from China Meteorological Data Sharing Service System(http://cdc.cma.gov.cn/home.do). The data set concluded the $10 \mathrm{~cm}$ soil moisture, $20 \mathrm{~cm}$ soil moisture., etc of the observation station from September, 1991 to October, 2012.

\section{B. The construction of the NDVI-Ts general space}

The studies of Goward, etc. (1985) and Sandholt, etc. (2002) showed that in a certain geographical, there may be effect of the absorbed surface net solar radiation to the surface temperature, however, the effect of the soil moisture and evapotranspiration. $\mathrm{Yu}(2011)$ point that, if there was no obvious changes in the types of the land cover, the multi-year remote sensing data could be used to construct the general space to avoid the instability with the single data. The process is as follows: 1) Based on the NDVI-Ts space for every single time, the dry side equation and wet side equation were constructed; 2) Based on the maximum synthesis and the minimum synthesis, the maximum Ts and minimum Ts were extracted as the general maximum Ts and the general minimum Ts; 3) Based on the extracted data, the general space was constructed, the dry side equation and the wet side equation were also extracted

$$
\mathrm{T}_{\mathrm{wet}_{\mathrm{i}}}=\mathrm{a}_{1}+\mathrm{b}_{1} \times \mathrm{I}_{\mathrm{NDV}_{\mathrm{i}}}
$$




$$
\mathrm{T}_{\mathrm{dry}_{\mathrm{i}}}=\mathrm{a}_{2}+\mathrm{b}_{2} \times \mathrm{I}_{\mathrm{NDV}}
$$

Where , $I_{N D V}$ was the NDVI, $T_{d r y_{i}}, T_{\text {wet }_{i}}$ were the Ts of the dry side and the wet side, $a_{1}, b_{1}, a_{2}, b_{2}$ were the intercept and slope of the dry side equation and wet side equation for the general space.

Based on the general space, the Temperature Vegetation Dryness Index (TVDI) was constructed as:

$$
\mathrm{TVDI}=\frac{\mathrm{T}_{\mathrm{s}}-\left(\mathrm{a}_{1}+\mathrm{b}_{1} \times \mathrm{I}_{\mathrm{NDV}}\right)}{\left(\mathrm{a}_{2}+\mathrm{b}_{2} \times \mathrm{I}_{\mathrm{NDV}}\right)-\left(\mathrm{a}_{1}+\mathrm{b}_{1} \times \mathrm{I}_{\mathrm{NDV}}\right)}
$$

\section{Results and disscussion}

\section{A. The construction of NDVI Ts general space}

In accordance with the methods introduced, the NDVI_Ts general space was constructed with the NDVI-step of 0.001 . The space constructed with single time was not stable, and there were much difference of the dry side and wet side equations in different years with the same vegetation cover. The Ts of dry side in the general space is commonly higher, and the Ts of wet side is commonly lower than that of single time, and the borders are relatively clear, the anomalies in wet side is significantly reduced.

Based on the constructed general space, the dry side equation and wet side equation were established in the Table.1. TVDI from 1981 and 2010 were calculated with the two equations.

Table. 1 The dry and wet equation in Ts-NDVI general space

\begin{tabular}{cccc}
\hline The period & The type of side & The equation & $\mathrm{R}^{2}$ \\
\hline \multirow{2}{*}{ 1981-1999 } & $\begin{array}{l}\text { Dry side } \\
\text { Wet side }\end{array}$ & $\begin{array}{c}\mathrm{Ts}=54.164-9.527 \mathrm{NDV} \\
\mathrm{Ts}=-2.305+25.421 \mathrm{NDV}\end{array}$ & 0.752 \\
& Dry side & $\mathrm{Ts}=43.052-17.055 \mathrm{NDV}$ & 0.786 \\
\hline \multirow{2}{*}{ Wet side } & $\mathrm{Ts}=-3.686+7.224 \mathrm{NDV}$ & 0.691 \\
& We-2012 & & 0.810 \\
\hline
\end{tabular}

\section{B. The precision test}

Based on the measured 10-d soil moisture $(10 \mathrm{~cm})$ data from 1991 to 2012, the precision test were conducted. The results showed that there was normal good relationship between the inverted TVDI and the measured soil moisture $(R>0.55)$. It could be indicated that TVDI could reflect the changes of soil moisture, and could be used as an effective index to evaluate soil moisture.

Table. 2 Relationship between TVDI and $10 \mathrm{~cm}$ soil moisture

\begin{tabular}{cccccccc}
\hline Year & 1992 & 1993 & 1994 & 1995 & 1996 & 1997 & 1998 \\
\hline $\mathrm{R}^{2}$ & 0.356 & 0.462 & 0.431 & 0.467 & 0.452 & 0.314 & 0.417 \\
\hline Year & 1999 & 2000 & 2001 & 2002 & 2003 & 2004 & 2005 \\
\hline $\mathrm{R}^{2}$ & 0.417 & 0.345 & 0.435 & 0.330 & 0.305 & 0.406 & 0.406 \\
\hline Year & 2006 & 2007 & 2008 & 2009 & 2010 & 2011 & 2012 \\
\hline $\mathrm{R}^{2}$ & 0.361 & 0.440 & 0.403 & 0.338 & 0.402 & 0.443 & 0.462 \\
\hline
\end{tabular}




\section{The spatio-temporal changes in TVDI}

The paper classified TVDI as 5 levels: extremely wet $(0<$ TVDI $\leq 0.2)$, $\operatorname{wet}(0.2<$ TVDI $\leq 0.4)$, normal $(0.4<$ TVDI $\leq 0.6)$, dry $(0.6<$ TVDI $\leq 08)$, extremely dry $(0.8<$ TVDI $\leq 1.0)$, and classified the study period as 7 periods: 1980s (1981-1984), 1985s (1985-1989)、1990s (1990-1994), 1995s (1995-1999), 2000s (2000-2004), 2005s (2005-2009), 2010s (2010-2012). The monthly mean TVDI in the growth season (April - October) were calculated from the $10 \mathrm{~d}$ or 16d TVDI data.

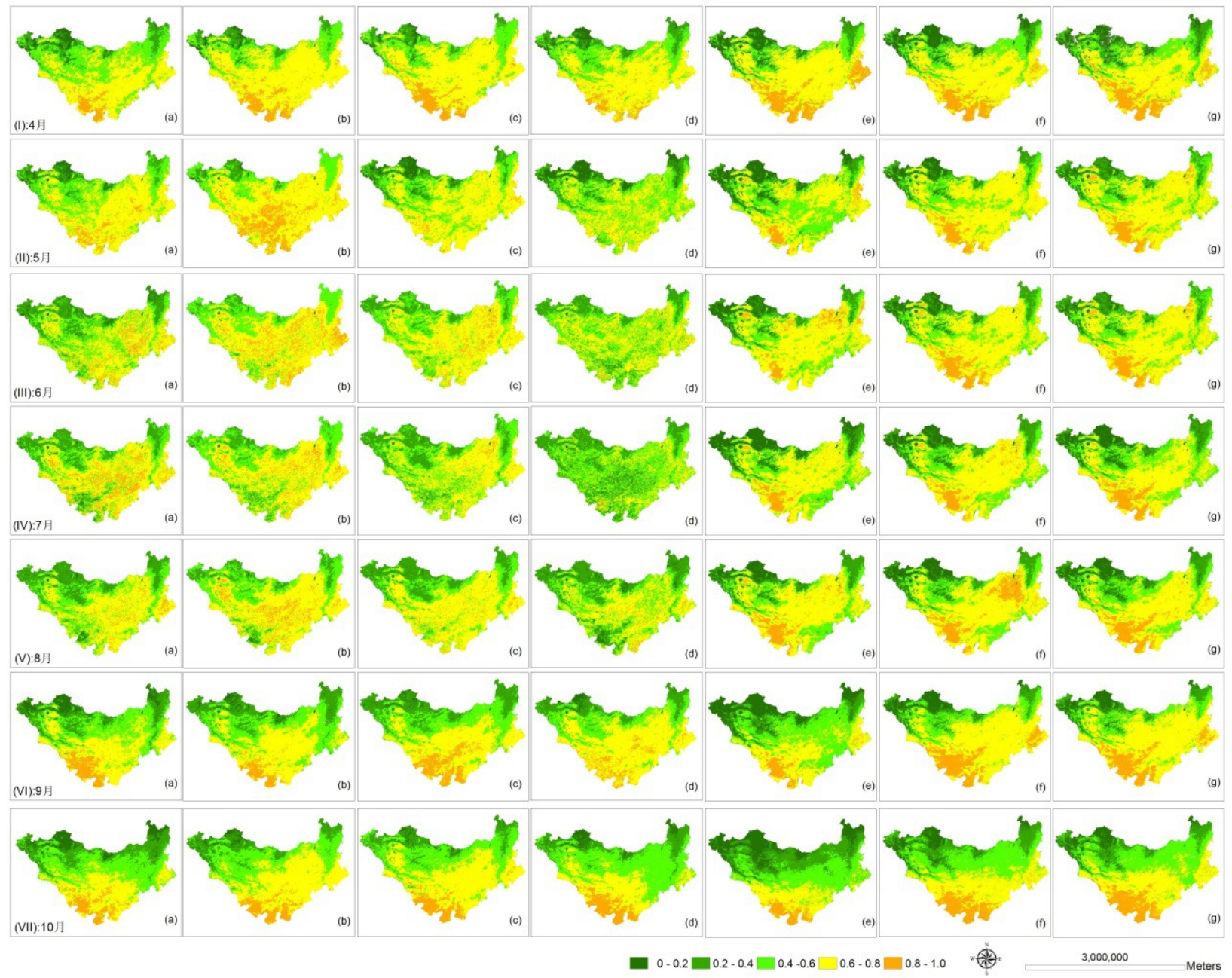

Fig. 2 The TVDI of different periods from April to October (I: Apr., II: May., III: Jun., IV: Jul., V: Aug., VI: Sep., VII: Oct; (a): 1980s, (b): 1985s, (c):1990s, (d):1995s, (e):2000s, (f):2005s, (g):2010s.)

Fig. 2 showed that TVDI presented zonal distribution with the changes of vegetation types, vegetation cover and latitude. TVDI was lower in the areas with high latitude, high vegetation cover, well-growing vegetation, which indicated higher soil moisture. However, TVDI was higher in the areas with low latitude, low vegetation cover, bad-growing vegetation, which indicated lower soil moisture. There were also relationship between TVDI and Land Use/Land Cover. In forest area, TVDI mainly showed as 
extremely wet and wet level; in the north and middle part of the Plateau, where distributed large area of grassland, TVDI mainly showed as normal level; in the southern area with low grassland, TVDI showed as dry level; in the northern area with bare land and desert, TVDI mainly showed as dry and extremely dry level.

The area of different level in every month changed in different period. The results showed that, in the period of 1981-2012, there were about averaged $130.94 \times 10^{4} \mathrm{~km}^{2}$ of area suffering drought every year in the Plateau, which accounted for $44.03 \%$ of the total area. The extremely dry area was about $22.24 \times 10^{4} \mathrm{~km}^{2}$ on average every year, accounting for $7.48 \%$ of the total area. The normal level area was about $83.18 \times 10^{4} \mathrm{~km}^{2}$ on average every year, accounting for $27.97 \%$ of the total area. The wet level area was about $43.57 \times 10^{4} \mathrm{~km}^{2}$, on average every year, accounting for $14.65 \%$ of the total area. The extremely wet level area was the least, only was $17.44 \times 10^{4} \mathrm{~km}^{2}(5.86 \%)$. Overall, the dry level area was the largest one, and the normal area was the second largest, the wet level area was the third, the extremely dry and extremely wet area was the least.

The paper named the extremely dry and dry level as the arid area, the extremely wet and wet area as the humid area. The results showed that, in the study period, the arid area varied from $112.88 \times 10^{4} \mathrm{~km}^{2}$ to $219.19 \times 10^{4} \mathrm{~km}^{2}$, accounted for about $37.96 \%-73.71 \%$ of the total area. The average value was $51.51 \%$, which indicated that the soil moisture was generally low in the Mongolian Plateau, the aridification was also widespread in this area, and it was serious in some period.

For the five levels, dry level accounted for the largest area proportion in the study period, which was about $47.98 \%$ averagely. The normal level $(27.70 \%)$ and the wet level( $13.70 \%)$ was the second and third largest, respectively. The extreme dry(4.29\%) and extreme wet level(5.18\%) was the least one in the study area. It was indicated that the soil moisture was generally low in the Mongolian Plateau. Furthermore, the area proportion of every level varied in different years. Generally, the dry level increased from 1981 to 2012 . In 1981, the area of dry level was about $97.29 \times 10^{4} \mathrm{~km}^{2}$, accounted for about $31.79 \%$ of the total area. In 2012 , the area of dry level was about $109.11 \times 10^{4} \mathrm{~km}^{2}$, accounted for about $36.69 \%$ of the total area.

In 1981 -1992, the area showed a sustainable increase. In 1992, the area of dry level was about 175.37x $10^{4} \mathrm{~km}^{2}$, accounted for about $58.97 \%$ of the total area. After that, it decreased to $102.81 \times 10^{4} \mathrm{~km}^{2}$ in 1997 , and increased from 1998. However, it decreased again in 2000, 2001 and 2002. After that, the area of dry level increased continuously. In the study period, the largest arid area occurred in 2007, which was $202.88 \times 10^{4} \mathrm{~km}^{2}$, accounting for about $68.23 \%$ of the total area. The second largest year was 2011 , the area of the arid area was $195.67 \times 10^{4} \mathrm{~km}^{2}$, accounting for about $65.80 \%$ of the total area. The wet level accounted for about $13.70 \%$ of the total area averagely, and it basically remained unchanged for the 30 
years. The normal level showed a slight decrease from $115.52 \times 10^{4} \mathrm{~km}^{2}$ in 1981 to $50.04 \times 10^{4} \mathrm{~km}^{2}$ in 2011.The results showed that the fluctuated area mainly occurred in the normal level and the dry level, the extremely wet level, the wet level and extremely dry level basically remained unchanged. It may be explored that, the aridification became more serious in the 1981 - 2012, the area transformation mainly occurred between the normal level and dry level.

\section{Conclusion}

Based on the NDVI-LST space method, the paper inverted TVDI from 1981 to 2010 in the Mongolian Plateau, the results showed that TVDI could reflect the changes of soil moisture, and could be used as an effective index to evaluate soil moisture.

TVDI presented zonal distribution with the changes of vegetation types, vegetation cover and latitude. TVDI was lower in the areas with high latitude, high vegetation cover, well-growing vegetation, which indicated higher soil moisture.

The area of different level in every month changed in different period. The dry level area was the largest one, and the normal area was the second largest, the wet level area was the third, the extremely dry and extremely wet area was the least.

In the study period, the arid area varied from $112.88 \times 10^{4} \mathrm{~km}^{2}$ to $219.19 \times 10^{4} \mathrm{~km}^{2}$, accounted for about $37.96 \%-73.71 \%$ of the total area. The average value was $51.51 \%$, which indicated that the soil moisture was generally low in the Mongolian Plateau, the aridification was also widespread in this area, and it was serious in some period.

The results showed that the fluctuated area mainly occurred in the normal level and the dry level, the extremely wet level, the wet level and extremely dry level basically remained unchanged. It may be explored that, the aridification became more serious in the $1981-2012$, the area transformation mainly occurred between the normal level and dry level.

\section{References:}

[1]. Becker F., Li Z.L., 1990. Toward a Local Split Window Method over Land Surface [J]. Int. J. Remote Sens. 11(3): 369-393.

[2]. Carlson, T. N., Gillies, R. R., Perry, E.M., 1994. A method to make use of thermal infrared temperature and NDVI measurements to infer surface soil water content and fractional vegetation cover [J]. Remote Sensing Review 9:161-173.

[3]. Cihar J., Huang F., 1994. Effect of Atmospheric Correction and Viewing Angle Restriction on AVHRR Composites [J]. Can. J. Remote Sens. 20(2):132-137.

[4]. Fridel, M. A. Davis, F. W., 1994. Source of variation in radiometric surface temperature over a tallgrass prairie[J]. Remote Sens. Environ 48:1-17.

[5]. Goetz S. J., 1997. Multi-sensor analysis of NDVI, surface temeerature and biophysical variables st a mixed grassland site. Int. J. Remote Sens. 18(1): 71-79. 
[6]. Goward S. N., Cruickhanks G. D., Hope A. S., 1985. Observed relation between thermal emission and reflected spectral radiance of a complex vegetated landscape. Remote Sens. Environ. 18: 137-146.

[7]. Goward S. N., Hope A. S., 1989. Evapotranspiration from combined reflected solar and emitted terrestrial radiation: Preliminary FIFE results from AVHRR data. Adv. Space. Res. 9: 239-249.

[8]. Holben, B., 1986. Characteristics of maximum-value composite images from temporal AVHRR data[J]. Int. J. Remote Sens (7):1417-1434.

[9]. Holben, B., 1986. Characteristics of maximum-value composite images from temporal AVHRR data[J]. Int. J. Remote Sens (7):1417-1434.

[10]. Josef Cihlar, Huang Ly, Zhangqing Li, Jing Chen, 1997. Multitemporal Multichannel AVHRR data sets for land Biosphere Studies-Artifacts and corrections [J]. Remote sensing of environment 60: 35-57.

[11]. Lambin E. F., Ehrlich D., 1996. The surface temperature-vegetation index space for land cover and land cover change analysis. Int. J Remote Sensing 17(3): 463-487.

[12]. Lee. T.Y., Kaufman, Y.J., 1986. Non-Lambertain Effects on Remote Sensing of Surface Reflectance and Vegetation Index [J]. IEEE Trans. Geosci. Remote Sen. GE-24:699-708.

[13]. Nernani , R.R. , Running, S. W, 1989. Estimation of surface resistance to evapotranspiration from NDVI and thermal-IR ACHRR data. Jouranl of Appl. Meteor 28 , 276-284

[14]. Price, J. C., 1990. Using spatial context in satellite data to infer regional scale evapotranspiration[J]. IEEE Transactions on Geoscience and Remote Sensing 28: 940-948.

[15]. Sobrino J. A., Coll C., Caselles V., 1991. Atmospheric Correction for Land Surface Temperature Using NOAA-11 AVHRR channel 4 and 5 [J]. Remote Sens. Environ. 38(1): 19-34. 